\title{
Marcos de desenvolvimento motor na primeira infância e profissionais da educação infantil
}

\author{
Vitor Antonio Cerignoni COELHO* \\ Ademir DE MARCO** \\ Rute Estanislava TOLOCKA ${ }^{* * *}$
}

*Universidade

Federal do Tocantins,

Miracema, TO, Brasil

**Faculdade de

Educação Física,

Universidade Estadual

de Campinas,

Campinas, SP, Brasil.

${ }^{* * *}$ Faculdade de

Ciências da Saúde,

Universidade Metodista

de Piracicaba,

Piracicaba, SP, Brasil.

\section{Resumo}

Estudos indicam que crianças no ensino infantil podem não atingir seu potencial de desenvolvimento, especialmente relacionado com o desenvolvimento motor. 0 objetivo deste estudo foi identificar 0 conhecimento de profissionais que atuam diretamente com as crianças, em creches e pré-escolas, sobre marcos de desenvolvimento motor e seu entendimento sobre meio ambiente para potencializar o desenvolvimento infantil. Um grupo randomizado de profissionais respondeu a um questionário, baseado na Escala Bayley III, para avaliação do desenvolvimento motor infantil e a uma questão aberta sobre ambiente. A pontuação média para os marcos do desenvolvimento motor relacionados a ações motoras finas, sensoriais e de percepção foi de $41 \%$ e de $45 \%$ em relação desenvolvimento motor grosso. Os profissionais pensaram o ambiente apenas em aspectos particulares, sem relacioná-los entre si. Verificou-se que a maioria dos profissionais era licenciada em pedagogia ou tinha ensino médio relacionado com pedagogia. Os resultados apontam para falta de conhecimento sobre desenvolvimento motor infantil e ambiente adequado, o que pode gerar pobre estimulação cotidiana dentro destas instituições e dificuldades de observar se a criança precisa de atenção especial ou intervenção. É necessário discutir-se mais o papel do professor de Educação Física no ensino infantil.

Palavras-Chave: Criança; Desenvolvimento Motor; Ambiente; Creche; Pré-Escola; Educação Física.

\section{Introdução}

Cerca de 250 milhóes de crianças no mundo, com até cinco anos de idade, não atingem o potencial adequado de desenvolvimento cognitivo, motor, psicosocial e apresentam baixa capacidade criativa ${ }^{1}$.

Bebês frequentadores de creches americanas apresentaram níveis negativos no desenvolvimento motor $^{2}$ e crianças americanas entre quatro e 12 anos de idade, demonstraram atrasos motores e cognitivos ${ }^{3}$.

No Brasil, foram identificados atrasos no desenvolvimento de habilidades grossas e finas, linguagem e aspectos sociais ${ }^{4,5}$, desempenho motor abaixo do esperado ${ }^{6}$, níveis questionáveis de desenvolvimento motor $^{7}$ e desempenho sensório-motor abaixo do esperado 8 .
Para que o potencial do desenvolvimento infantil seja atingido adequadamente é necessário um ambiente favorável e estimulante, o que inclui possibilidades de interação social, experiências, descobertas e vivências motoras ${ }^{9}$, bem como um ambiente que propicie o desenvolvimento integral das crianças e uma educação de qualidade ${ }^{10}$.

Mudanças sociais têm levado crianças cada vez mais cedo para a escola, no Brasil é obrigatória a matrícula a partir de quatro anos de idade na Educação Infantil ${ }^{11}$. As crianças passam boa parte do seu dia nestes ambientes ${ }^{12}$, entretanto, estar matriculado ou frequentar instituiçóes infantis não garante o pleno desenvolvimento ${ }^{13,14} \mathrm{e}$ também 
existem problemas na formação dos profissionais que atuam neste nível de ensino ${ }^{15}$.

Algumas pesquisas têm verificado a dificuldade e o desconhecimento destes profissionais quanto aos domínios motores e cognitivos das crianças, por exemplo:Volpato eMeLLo ${ }^{16}$ realizaram umlevantamento em instituiçóes infantis para implantação de cursos de capacitação e verificaram que os profissionais estão mais preocupados com aspectos voltados para alfabetização do que aqueles que envolvam o desenvolvimento integral das crianças. SouZA ${ }^{17}$ entrevistou professoras da educação infantil e encontrou visão unidirecional do desenvolvimento, com dificuldades de identificar as características motoras, cognitivas e sociais. Duzzi e colaboradores ${ }^{18}$ verificaram que professores dos primeiros anos do ensino fundamental desconhecem as funções e habilidades psicomotoras das crianças.

Entretanto, segundo a Organização das Naçóes Unidas, avaliações de marcos do desenvolvimento motor ${ }^{19}$ são necessárias para garantir educação de qualidade, pois o cuidado e os estímulos adequados recebidos nos primeiros anos de vida, bem como a aquisição de habilidades motoras dentro do esperado são fatores positivos para melhorar a funçáo cognitiva e o desempenho escolar em idades posteriores ${ }^{20,21}$.

Desta maneira, torna-se importante que as professoras que atuam diretamente com as crianças no ensino infantil, conheçam as ações consideradas como marcos do desenvolvimento em concordância com suas faixas etárias, para que possam potencializar o desenvolvimento infantil, oferecendo atividades motoras adequadas e, quando necessário, realizar encaminhamentos a serviços especializados. Porém, pouco se sabe sobre o conhecimento de professores do ensino infantil sobre os marcos motores do desenvolvimento.

Assim, o objetivo deste estudo foi identificar o conhecimento de profissionais que atuam diretamente com as crianças em escolas infantis sobre marcos de desenvolvimento motor e o entendimento sobre o meio ambiente para potencializar este desenvolvimento.

\section{Método}

Trata-se de um estudo de campo exploratório, realizado em escolas da rede municipal de ensino infantil de uma cidade do interior Paulista, aprovado pelo comitê de ética e pesquisa de uma universidade, com parecer $n^{\circ} .13 / 12$.

A cidade possui aproximadamente $400 \mathrm{mil}$ habitantes; mais de 8 mil alunos matriculados na pré-escola; com Produto Interno Bruto (PIB) entre os 50 maiores do país; índice de desenvolvimento humano de 0,785 e economia fundada na indústria, agricultura e prestação de serviços ${ }^{22}$. Esta cidade oferece serviços públicos de apoio à educação e ao cuidado das crianças desde meados de 1950 e tem perfil semelhante a várias outras cidades do país.

\section{Participantes}

O estudo contou com a participação de 54 profissionais que atuam diretamente com crianças entre zero e cinco anos de idade. Esses foram sorteados, em número equivalente, nas cinco regiôes da referida cidade e assinaram o termo de consentimento livre esclarecido para participar do estudo. Todos os profissionais eram do sexo feminino e regentes de sala.

\section{Instrumentos e procedimentos}

Os profissionais sorteados foram convidados a participar de um evento pedagógico que recebeu o apoio da Secretaria de Educaçáo Municipal, a atividade foi realizada em uma Universidade pertencente ao município e na ocasião os profissionais foram informados dos objetivos do estudo.

Os dados foram coletados através de um questionário elaborado para fins deste estudo, conforme as recomendaçôes de LUDKE e ANDRE ${ }^{23}$. Tal questionário continha 15 questôes fechadas, onde em cada pergunta se apresentava uma ação motora (grossa ou fina, sensitiva e perceptiva) e se solicitava a escolha de apenas uma das seguintes faixas etárias: 1 a 3 meses; 4 a 8 meses; 9 a 12 meses; a partir de 12 meses; a partir de 19 meses; a partir de 24 meses ou partir de 36 meses. As açóes indagadas foram: Rabiscar desenhos; Movimentos de pinça; Encaixar objetos em orifícios; Cortar papel com tesoura; Desenhar formas básicas; Construir pontes e torres com blocos; Movimentar os membros inferiores e superiores; Sustentar a cabeça por mais tempo; Ficar em pé com apoio; Ficar de joelhos; Engatinhar; Subir degraus com apoio sem alternar os pés; Subir e descer escadas alternando os pés; Chutar uma bola; Equilibrar sobre um dos pés. 
Estas ações ocorrem em faixas etárias específicas, conforme proposto pela Escala Bayley III (Bayley Scales of Infant and Toddler Development-III $)^{24} \mathrm{e}$ a resposta foi considerada correta se coincidisse com a faixa etária proposta nesta escala. Esta escala foi escolhida porque tem sido utilizada amplamente para detecçáo de problemas de desenvolvimento na primeira infância, tanto em países desenvolvidos, quanto em países emergentes, tais como o Brasil, e baseia-se em conhecimentos de neurologia e desenvolvimento infantil. Sendo assim, os marcos deste teste foram considerados como parâmetros para a contagem de acertos e erros, que denotaria o conhecimento ou não dos marcos desenvolvimentais neles contidos.

Foi atribuído para cada acerto o valor numérico 2 e para cada erro o valor numérico 1 em todas as questóes assinaladas pelos profissionais, também foi efetuado a soma das questóes certas e erradas.

Para verificar se houve correspondência entre a ocorrência da ação e a faixa etária para que isso ocorra foi realizado o cálculo Euclidiano de distância entre estas duas variáveis (acertos e erros/ faixa etária esperada) ${ }^{25}$.

O questionário incluía, também, uma questão aberta: "cite os principais aspectos que devem ser observados para verificar se o ambiente é favorável ao desenvolvimento infantil”. Esta questão foi analisada qualitativamente com base na construção de uma matriz de análise para categorização dos temas mais relevantes indicados pelos profissionais nos diferentes domínios do desenvolvimento infantil (físico, motor, social, cognitivo e afetivo) e a relação com o ambiente.

\section{Resultados}

Os marcos de desenvolvimento motor mais identificados foram: movimentar os membros inferiores e superiores, que ocorre entre um a três meses de vida e cortar papel com tesoura, que se inicia a partir dos 36 meses de idade, indicados respectivamente por $87 \%$ das profissionais em ambas as questóes. Os movimentos de pinça com os dedos e encaixe de objetos grandes foram os que tiveram menor índice de identificação, apenas $7 \%$ das profissionais indicaram que esta atividade se inicia a partir do $12^{\circ}$ mês de vida.

Marcos motores como: ficar de joelhos, engatinhar, rabiscar desenhos, subir e descer escadas, chutar uma bola, equilibrar sobre um dos pés, ou construir pontes e torres com blocos, não foram identificados adequadamente por mais de $61 \%$ do grupo. O maior número de acertos foi o de $87 \%$ para as atividades de cortar papel com tesoura e movimentar os membros inferiores e superiores, e o menor foi de $7 \%$ na ação motora fina de pinça.

A distribuição de respostas corretas, de acordo com os marcos de desenvolvimento motor, indicados por Bayley III ${ }^{24}$, pode ser vista na TABELA 1.

Entre as respostas que relacionavam ambiente ao espaço físico, algumas se voltaram aos elementos de assistência à criança, tais como a da Profissional (P) 10: "espaço amplo, arejado e seguro para desenvolver as atividades"; P15: "espaço organizado, limpo, iluminado e estimulante" e P24: "piso, iluminação, mobiliário, ventilação, higiene”.

TABELA 1 - Distribuição relativa das ações identificadas na faixa etária esperada, de acordo com os marcos de desenvolvimento motor, indicados por Bayley $\mathrm{III}^{24}$

\begin{tabular}{llc}
\hline Marco desenvolvimental & Faixa etária & \% respostas certas \\
\hline 1- Açóes motoras finas, sensitivas e perceptivas & & \\
Rabiscar desenhos & a partir de 12 & 15 \\
Movimentos de pinça & a partir de 12 & 7 \\
Encaixar objetos em orifícios & a partir de 24 & 37 \\
Cortar papel com tesoura & a partir de 36 & 87 \\
Desenhar formas básicas & a partir de 36 & 68 \\
Construir pontes e torres com blocos & a partir de 36 & 35 \\
2- Açóes motoras grossas, sensitivas e perceptivas & & \\
Movimentar os membros inferiores e superiores & entre 1 a 3 & 87 \\
\hline & & Continua
\end{tabular}


Continuação

TABELA 1 - Distribuição relativa das ações identificadas na faixa etária esperada, de acordo com os marcos de desenvolvimento motor, indicados por Bayley III $^{24}$

\begin{tabular}{lcc}
\hline Marco desenvolvimental & Faixa etária & \% respostas certas \\
\hline Sustentar a cabeça por mais tempo & entre 4 a 8 & 74 \\
Ficar em pé com apoio & entre 9 a 12 & 67 \\
Ficar de joelhos & entre 9 a 12 & 28 \\
Engatinhar & entre 9 a 12 & 35 \\
Subir degraus com apoio sem alternar os pés & a partir de 19 & 24 \\
Subir e descer escadas alternando os pés & a partir de 36 & 39 \\
Chutar uma bola & a partir de 24 & 17 \\
Equilibrar sobre um dos pés & a partir de 24 & 39 \\
\hline
\end{tabular}

O cálculo Euclidiano de distâncias foi de 28,8, o que indicou dissimilaridade entre as matrizes de acerto e erro, ou seja, a proporçáo de erros foi maior do que a de acertos, o que representou uma dificuldade das professoras em corresponder as faixas etárias esperadas pela literatura com a ocorrência das açóes motoras adequadas aos marcos de desenvolvimento.

Com relaçáo a pergunta aberta sobre "aspectos necessários para um ambiente favorável ao desenvolvimento infantil", observou-se que o termo "ambiente" foi associado ao termo "espaço" por 40, das 54 profissionais. O significado de "espaço" foi diversificado, destacando-se a relação estabelecida entre ambiente e aspecto físico, ou ambiente e ludicidade, porém na maioria das vezes isoladamente, sem mençáo a outros aspectos igualmente presentes no ambiente, tais como possibilidades de relacionamentos interpessoais, desafios para vivência de papéis sociais ou de solução de problemas.

Entre as respostas que relacionavam ambiente ao espaço físico, algumas se voltaram aos elementos de assistência à criança, tais como a da Profissional (P) 10: "espaço amplo, arejado e seguro para desenvolver as atividades"; P15: "espaço organizado, limpo, iluminado e estimulante" e P24: "piso, iluminação, mobiliário, ventilação, higiene”.

Outras respostas estavam relacionadas aos espaços físicos com áreas externas e presença de locais verdes como gramados, árvores, flores e hortas, como por exemplo, P16: "espaço físico externo adequado para explorar, com árvores e gramado" ou P31: "espaço amplo com grama, canteiros de flores".

No domínio motor, o termo espaço foi utilizado em referência às possibilidades de movimento e ou prática de atividade física, como o expressado pelas profissionais P16: "é necessário ter espaços adequados para se movimentar, como plano, tanque de areia e parque"; P38: "espaço físico, seguro e adequado para a atividade física" e P25: "espaço para se locomover, tenha liberdade para explorar o próprio ambiente, correr, pular, dançar".

Este termo também foi utilizado em relação as atividades lúdicas: P25: "espaço para brincar em atividade lúdica" P43: "espaço físico, materiais, jogos e brinquedos"; P47: "espaço para atividades lúdicas" e P48: "espaço, materiais, conhecimento e brinquedos".

O conceito de ambiente/espaço também foi relacionado, por 13 profissionais, com aspectos pedagógicos, no que se refere à necessidade de atividades e materiais adequados. Entre as respostas podem ser citadas P13: "espaços adequados para o professor realizar suas atividades, seus componentes e materiais" ou da P51: "espaço físico amplo, ambiente acolhedor, recursos e materiais adequados à idade”.

Apenas quatro profissionais vincularam o ambiente com a possibilidade de estimulação de diferentes aspectos, P14: "ambiente que estimule a coordenação viso-motora, agilidade e cooperação da criança”; P21: "ambiente que estimule a motricidade, lateralidade, reflexo, raciocínio lógico e linguagem"; P28: "ambiente que oferece condiçóes de desenvolvimento cognitivo, sócio-afetivo, motor e atenda aos interesses da criança, favorável à descobertas e ao brincar" e P33: "deve ter campo de areia, espaço para as crianças correr e brincar, brinquedos que estimulem e desenvolvimento físico e motor". 


\section{Discussão}

Verifica-se que a maioria das professoras desconhece a maior parte dos marcos motores do desenvolvimento infantil, determinados pela Escala Bayley $\mathrm{III}^{24}$, pois o nível médio de acertos não chegou a $50 \%$ nem das questóes sobre açóes motoras finas e também das ações motoras grossas.

Chama atenção que a faixa etária prevista para início das açóes que exigem movimentos de pinça, encaixe de objetos grandes, rabiscar desenhos, construir torres e pontes com blocos ou encaixar objetos em orifícios não foi identificado pela maioria dos profissionais. No entanto, estudos sobre a rotina de crianças, no interior de instituiçóes de educação infantil desta região, apontam que estas açóes motoras manuais estão entre as mais realizadas nestes ambientes, mesmo os trabalhos não verificando como se dá a execução destas atividades, tornamse necessárias outras pesquisas que observem como as atividades estão se desenvolvendo e se estão adequadas as crianças as quais tem sido aplicada ${ }^{26,27}$.

Mesmo açóes como chutar uma bola, amplamente praticada na cultura brasileira, ou mesmo açôes do dia a dia, como subir escadas, com apoio, sem alternar os pés, ou alternando-os, também não foram indicadas conforme esperado para o desenvolvimento infantil. O desenvolvimento das habilidades motoras grossas e de locomoção são fundamentais para aquisição de repertório motor necessário para realização de atividades diárias, melhora da competência motora e futuramente para engajamento em práticas esportivas e recreativas ${ }^{28}$.

No que tange à concepção de ambiente a maioria dos profissionais ainda vincula ambiente ao aspecto físico do espaço onde as atividades ocorrem. Há uma carência de relaçóes entre os diferentes aspectos do desenvolvimento que o ambiente pode influenciar; não foram feitas associaçôes entre as propriedades físicas e as características das crianças, o que inclui, habilidades motoras, condiçóes clínicas, manifestações emocionais e interaçóes sociais, dentre outras ${ }^{29}$.

É importante ressaltar que o ambiente de uma instituição infantil vai muito além do espaço físico no qual elas se encontram, ele possibilita a interação entre a pessoa-contexto-processo-tempo?. Desta forma, precisa ser considerado que a criança irá estabelecer relaçôes sociais com outras pessoas presentes no ambiente, ao mesmo tempo em que fará uso de suas características pessoais, representará papéis sociais e realizará atividades para dar conta das demandas ambientais propostas.

Os profissionais devem ser os mediadores dos processos proximais primários do ambiente ${ }^{30}$ onde a criança está, ou seja, devem estar aptos para organizar o ambiente favorecendo os diferentes aspectos do desenvolvimento, porém, se a concepção de ambiente é limitada o preparo do mesmo também poderá estar comprometido.

As restrições ambientais podem levar a limitaçôes de tempo e espaço para realização de práticas motoras, provocando riscos para o desenvolvimento e aquisição de patologias, tais como, obesidade, problemas cardíacos e respiratórios ${ }^{31,32}$.

Muitas das atividades realizadas nas escolas infantis não promovem o desenvolvimento integral e não respeitam a natureza lúdica e criativa por parte das crianças ${ }^{33}$. Outros estudos indicam que as açóes realizadas nestas unidades de ensino ainda são predominantemente assistencialistas, quando não são exageradamente escolarizantes ${ }^{13,34}$, sem oferecer oportunidades de movimentação corporal, instrução e estímulos adequados ao desenvolvimento pleno da infância ${ }^{35}$.

Assim, simplificações sobre meio ambiente associadas ao desconhecimento de marcos do desenvolvimento motor podem redundar em oferta de experiências pobres e restringir o desenvolvimento da criança. A dificuldade em conhecer os marcos das açóes motoras finas, grossas, sensitivas e perceptivas poderá acarretar que atrasos no desenvolvimento passem despercebidos, dificultando o reconhecimento de necessidade de intervençấo ou encaminhamentos a serviços especializados ${ }^{8}$.

Vale lembrar que, na maioria das vezes, o parâmetro de acompanhamento adotado nas instituiçôes infantis é o da comparação entre as próprias crianças ${ }^{36,37}$, o que pode acentuar falhas na identificação de déficits motores e impedir o enriquecimento de programas que estimulem as crianças. Isto dificulta o cumprimento da emenda $12796 / 13$, que inclui entre as atribuições dos profissionais, avaliaçóes e registros de acompanhamento do desenvolvimento dos alunos, uma vez que todos os aspectos do desenvolvimento infantil devem ser igualmente avaliados ${ }^{20}$.

Uma explicação para a dificuldade dos profissionais em indicar a ocorrência esperada dos 
marcos de desenvolvimento motor, encontra-se nos currículos de formação em licenciatura ligados ao ensino infantil ${ }^{36,37}$. Na maioria dos cursos de licenciatura não constam disciplinas que tratem das especificidades do desenvolvimento motor e neuropsicológico das crianças pequenas, exceção feita à cursos de Educação Física, o que já havia sido apontado em estudos anteriores ${ }^{15}$.

Particularmente no presente estudo, a maioria das profissionais tinham formação em pedagogia/ normal superior e as demais tinham formaçôes em áreas afins, o que indica a ausência de outras licenciaturas nas instituiçóes estudadas. Cabe aqui a discussão sobre a necessidade de diversificação profissional, prevista pela emenda n. ${ }^{\circ} 12796 / 13$ para este nível de ensino, bem como a importância da revisão de currículos de cursos de formação e graduaçáo que preparam profissionais para atuar neste nível de ensino ${ }^{11}$.

O debate sobre o papel da Educação Física neste nível de ensino deve levar em consideração a necessidade de propiciar ambiente estimulador e práticas motoras para potencializar o desenvolvimento infantil.

Pesquisas realizadas com a inserção da Educação Física e um ambiente voltado para a prática de movimentos no ensino infantil têm apresentado indícios positivos da participação deste profissional junto a esta primeira etapa da Educação Básica ${ }^{35,38}$, até mesmo para fazer parte de uma equipe multidisciplinar que estimule desde cedo hábitos saudáveis que elevem os níveis de atividade física das crianças pequenas e afastem-nas de comportamentos sedentários que prejudicam a saúde.

Mudanças no número de horas de estágio, visando aperfeiçoar a formaçáo do professor, colocando-o em contato direto com as questôes diárias de seu exercício profissional, foram propostas na deliberação do Conselho Nacional de Educação (CEE) no. 126/14, mas para que se tornem eficientes, os estágios devem ocorrer em trabalhos com equipes que possuem profissionais que já tem conhecimento desses marcos de desenvolvimento infantil ${ }^{39}$.

É oportuno lembrar que o saber acerca dos marcos do desenvolvimento motor na infância também é reconhecido pelas áreas médicas e fisioterápicas, que consideram importante estes saberes para diagnóstico, prevenção e intervenção do desenvolvimento infantil ${ }^{40}$. Estes requisitos podem incrementar políticas públicas entre diferentes setores, troca de informações e conhecimento bem como a realização de trabalhos coletivos com a educaçáo infantil.

Estas mudanças podem colaborar para que os profissionais, que estão em contato direto e diário com as crianças, promovam estimulaçóes de forma natural e adequada, como também estejam aptos para identificar possíveis casos de déficits de desenvolvimento, para com isto procederem aos devidos encaminhamentos especializados.

Ressalta-se ainda que atrasos ou déficits motores podem comprometer açóes no cotidiano infantil e propagarem-se pela vida adulta, razáo pela qual, esforços devem ser feitos para evitá-los.

Embora o questionário utilizado esteja diretamente relacionado a um instrumento validado no exterior e utilizado amplamente, inclusive no Brasil, para fins de avaliação de desenvolvimento motor, ressalvase aqui que a escala Bayley III $^{24}$ não foi ainda validada no Brasil, o que requer que os dados aqui apresentados sejam considerados com cautela, e reforça a necessidade de estudos para validação de instrumentos de avaliação de desenvolvimento motor de crianças brasileiras.

\section{Abstract}

\section{Stages of motor skills development during early childhood and their impact on education}

Studies have indicated that children attending early schools may not reach their potential development, specially related with motor development. The aim of this study was to identify the knowledge of professionals who work directly with children in kindergartens and pre-schools, on motor development milestones and their understanding of the environment to enhance child development. A randomized group of professionals answered a questionnaire, based in the Bayley III scale for evaluation of the motor development and an open question about environment and child development. The mean score for motor development milestones related to fine motor actions, sensory and perceptual was $41 \%$ and it was $45 \%$ related to gross motor development milestones. They thought environment in particular aspects, without relationship among them. It was verified that the professionals had pedagogy degree or high school level related with. The results point out the lack of knowledge about child motor development and adequate environment among such 
professionals. It may produce poor stimulation in daily life as well difficulties to observe if the children needs special attention/intervention. It is necessary to discuss more the role of a physical educator teacher in the children education.

KEYwORDS: Child; Motor Development; Environment; Nursery; Kindergarten; Physical Education.

\section{Referências}

1. Black MM, Walker SP, Fernald LCH, et al. Early childhood development coming of age: science through the life course. Lancet. 2017;389(10064):77-90.

2. Duncan GJ, National Institute of Child Health and Human Development Early Child Care Research Network. Modeling the impacts of child care quality on children's preschool cognitive development. Child Dev. 2003;74(5):1454-75.

3. Belsky J, Vandell DL, Burchinal M, Clarke-Stewart KA, McCartney K, Owen MT. Are there long-term effects of early child care? Child Dev. 2007;78(2):681-701.

4. Biscegli TS, Polis LB, Santos LM, Vicentin M. Avaliaçáo do estado nutricional e do desenvolvimento neuropsicomotor em crianças freqüentadoras de creche. Rev Paul Pediatr. 2007; 25(4):337-42.

5. Baltieri L, Santos DCC, Gibim NC, Souza CT, Batistela ACT, Tolocka RE. Desempenho motor de lactentes frequentadores de berçários em creches públicas. Rev Paul Pediatr. 2010;28(3):283-9.

6. Schobert L. O desenvolvimento motor de bebês em creches: um olhar sobre diferentes contextos [dissertação]. Porto Alegre (RS): Universidade Federal do Rio Grande Sul; 2008.

7. Souza CT, Santos DCC, Tolocka RE, Baltieri L, Gibim NC, Habechian FAP. Avaliaçáo do desempenho motor global e em habilidades motoras axiais e Apendiculares de lactentes frequentadores de creche. Rev Bras Fisioter. 2010;14(4):309-15.

8. Soejima CS, Bolsanello MA. Programa de intervenção e atenção precoce com bebês na educação infantil. Educ Rev. 2012;43:65-79.

9. Bronfenbrenner $U$. The bioecological theory of human development. In: Bronfenbrenner $U$, organizer. Making human beings human: bioecological perspectives on human development. Thousand Oaks: Sage; 2005. p. 106-73.

10. Fundo das Naçôes Unidas para a Infância. Convençấo sobre os direitos da criança [Internet]. 1989 [citado 2016 mar 30]. Disponível em: https://www.unicef.org/brazil/convencao-sobre-os-direitos-da-crianca.

11. Brasil. Lei no 12.796, de 4 de abril de 2013: altera a Lei no 9.394, de 20 de dezembro de 1996, que estabelece as diretrizes e bases da educação nacional, para dispor sobre a formação dos profissionais da educação e dar outras providências. Diário Oficial da Uniāo [Internet]. 5 abr 2013 [citado 15 mar 2016]. Disponível em: https://www2.camara.leg.br/legin/fed/lei/2013/ lei-12796-4-abril-2013-775628-publicacaooriginal-139375-pl.html.

12. Rezende MA, Costa PS, Pontes PB. Triagem de desenvolvimento neuropsicomotor em instituiçóes de educaçáo infantil segundo o teste de Denver II. Esc Anna Nery. 2005;9(3):348-55.

13. Barbosa MCS. Por amor e por força: rotinas na educação infantil. Porto Alegre: Artmed; 2008.

14. Campos MM, Esposito YL, Bhering E, Gimenes N, Abuchaim B. A qualidade na educação infantil: um estudo em seis capitais Brasileiras. Cad Pesqui. 2011;41(142):20-54.

15. Gatti BA. Formação de professores no Brasil: características e problemas. Educ Soc. 2010;31(113):1355-79.

16. Volpato CF, Mello SA. Trabalho e formação dos educadores de creche em Botucatu: reflexóes críticas. Cad Pesq. 2005;35(126):723-45.

17. Souza NN. Concepçóes de educadoras de creche sobre o desenvolvimento da criança na faixa etária de zero a três anos [dissertaçāo]. Curitiba (PR): Universidade Federal do Paraná, 2008.

18. Duzzi MHB, Rodrigues SD, Ciasca SM. Percepçáo de professores sobre a relaçáo entre desenvolvimento das habilidades psicomotoras e aquisiçẫo da escrita. Rev Psicopedag. 2013;30(92):121-8.

19. Wijnhoven TM, De Onis M, Onyango AW, et al. Assessment of gross motor development in the WHO Multicentre Growth Reference Study. Food Nutr Bull. 2004;25(1 Suppl):37-45.

20. Piek JP, Dawson L, Smith LM, Gasson N. The role of early fine and gross motor development on later motor and cognitive ability. Hum Mov Sci. 2008;27(5):668-81.

21. Vandell DL, Belsky J, Burchinal M, Vandergrift N, Steinberg L. Do Effects of Early Child Care Extend to Age 15 Years? Results From the NICHD Study of Early Child Care and Youth Development. Child Dev. 2010;81(3):737-56. 
22. Instituto Brasileiro de Geografia e Estatística. Brasil em Síntese | São Paulo | Piracicaba | Panorama [Internet]. Rio de Janeiro: IBGE; 2010 [citado 30 mar 2016]. Disponível em: http://www.cidades.ibge.gov.br/xtras/perfil.php?lang=\&codmun=3538 70\&search=sao-paulo|piracicaba|infograficos:-informacoes-completas.

23. Ludke M, André MEDA. Pesquisa em educação: abordagens qualitativas. São Paulo: Pedagógica e Universitária; 1986.

24. Bayley N. Bayley scales for infant development III. San Antonio: The Psychological Corporation; 2006.

25. Thomas J, Nelson JK. Métodos de pesquisa em atividade física. Porto Alegre: Artmed; 2002.

26. Tolocka RE, Horita KY, Oliveira CB, Coelho VAC, Santos DCC. Como brincar pode auxiliar no desenvolvimento de crianças pré-escolares. Licere. 2009;12(1):30-51.

27. Faria MCM, Brolo ALR, Horita KY, Tolocka RE, Santos DCC, Silva JVP. Atividades motoras cotidianas e suas influências no desenvolvimento de pré-escolares. Movimento (Porto Alegre). 2010;16(1):113-30.

28. Braga RK, Krebs RJ, Valentini NC, Tkac CM. A influência de um programa de intervençáo motora no desempenho das habilidades locomotoras de crianças com idade entre 6 e 7 anos. Rev Educ Fís UEM. 2009;20(2):171-81.

29. Spessato BC, Valentini NM, Krebs RJ, Berleze A. Educação infantil e intervenção motora: um olhar a partir da teoria bioecológica de Bronfenbrenner. Movimento. 2009;15(4):149-76.

30. Krebs RJ. Bronfenbrenner's Bioecological Theory of Human Development and the process of development of sports talent. Int J Sports Psychol. 2009;40(1):108-35.

31. Kohl HW, Craig CL, Lambert EV, et al. The pandemic of physical inactivity: global action for public health. Lancet. 2012;380(9838):294-305.

32. Simon VGN, Souza JMP, Leone C, Souza SB. Prevalência de sobrepeso e obesidade em crianças de dois a seis anos matriculadas em escolas particulares no município de São Paulo. Rev Bras Crescimento Desenvolv Hum. 2009;19(2):211-8.

33. Kishimoto TM. Educação infantil no Brasil e no Japão: acelerar o ensino ou preservar o brincar? Rev Bras Est Pedag. 2009;90(225):449-67.

34. Bógus CM, Nogueira-Martins MCF, Moraes DEB, Taddei JAAC. Cuidados oferecidos pelas creches: percepçóes de mães e educadoras. Rev Nutr. 2007;20(5):499-514.

35. Andrade Filho NF. Observação compreensivo-crítica das experiências de movimento corporal das crianças na educação infantil. Movimento. 2013;19(1):55-71.

36. Kramer S, Toledo LPB, Barros C. Gestão da Educação Infantil nas políticas municipais. Rev Bras Educ. 2014;19(56):11-36.

37. Guirra FJS, Prodocimo E. Trabalho corporal na educação infantil: afinal, quem deve realizá-lo? Motriz. 2010;16(3):708-13

38. Lemos AG, Avigo EL, Barela JA. Physical Education in kindergarten promotes fundamental motor skill development. Adv Phys Educ. 2012;2(1):17-21.

39. São Paulo. Conselho Estadual de Educação. Secretaria Estadual de Educação. Deliberação CEE no 126/2014, de 5 de junho de 2014. Diário Oficial do Estado de São Paulo [Internet]. 5 jun 2014 [citado 15 mar 2016]. Disponível em: http://www. ccg.unicamp.br/files/cpfp/legislacao/Deliberacao_CEE_SP_126_2014.pdf.

40. Rodrigues OMPR. Escalas de desenvolvimento infantil e o uso com bebês. Educ Rev. 2012;43:81-100.

ENDEREÇO
Vitor Antonio CoelhoAvenida NS 15, 109 Norte -
Plano Diretor Norte - 77001-09o
Palmas - TO - BRASIL
e-mail: v7coelho@yahoo.com.br
Recebido para publicação: 23/05/2016

Revisão: 29/08/2017

Aceito: 09/04/2018 